\title{
Benthic and pelagic dives: a new foraging behaviour in rockhopper penguins
}

\author{
Yann Tremblay, Yves Cherel* \\ Centre d'Etudes Biologiques de Chizé, UPR 1934 du Centre National de la Recherche Scientifique, 79360 Villiers-en-Bois, France
}

\begin{abstract}
The pattern and characteristics of diving of 55 daily foraging trips performed by 16 female southern rockhopper penguins Eudyptes chrysocome filholi were studied in coastal waters of Kerguelen Archipelago during the guard stage. Diving patterns and dive profiles indicated that birds used 2 foraging behaviours. First, they performed typical pelagic dives, as previously decribed for other penguin species. Second, they also performed series of consecutive square-wave dives reaching similar maximum depths, with no deeper dives within the series, all criteria which characterized benthic dives. Two groups of benthic and pelagic dives were subsequently selected to compare their parameters. In agreement with optimization concepts in foraging theory, rockhopper penguins maximize bottom time (= feeding time) of benthic dives through an increase in both descent and ascent rates, thus minimizing transit time between the sea surface and the bottom. Regardless of dive depth, bottom time was longer and diving efficiency higher in benthic dives than in pelagic ones. Penguins were also more active during benthic dives, as indicated by higher numbers of depth and light wiggles at the bottom of these dives. Bathymetry and dive depth indicate that penguins were able to reach about $80 \%$ of the sea floor surrounding the colony. Abrupt changes in dive depth within series of benthic dives were identical in height to the thickness of lava flows, the main geological features of the landscape, strongly suggesting that birds followed the bottom topography at a fine scale. Dietary analysis showed that rockhopper penguins fed upon benthic prey (a few fish and the mysid Mysidetes morbihanensis) and pelagic organisms, including the major item Euphausia vallentini. There was a positive linear relationship between the mass of food brought ashore and an index of the proportion of benthic dives during the daily trips, thus emphasizing the importance for rockhopper penguins living in a coastal marine environment of feeding on pelagic migrators trapped at or near the sea floor during the day.
\end{abstract}

KEY WORDS: Eudyptes chrysocome filholi $\cdot$ Optimization · Euphausia vallentini $\cdot$ Kerguelen Islands

\section{INTRODUCTION}

The profile of the dives together with prey analysis indicate that penguins are macrozooplanktonic and micronektonic feeders, mainly preying upon swarming crustaceans and shoaling fish in the pelagic environment during the daylight hours (see review in Croxall \& Lishman 1987, Williams 1995, Wilson 1995). Conversely, evidence that penguins forage in the benthic marine environment is sparse. Some species, namely the gentoo penguin Pygoscelis papua (Adams \&

${ }^{*}$ Corresponding author. E-mail: cherel@cebc.cnrs.fr
Klages 1989, Ridoux 1994, Robinson \& Hindell 1996), yellow-eyed penguin Megadyptes antipodes (Seddon \& Van Heezik 1990, Van Heezik 1990, Moore \& Wakelin 1997) and the emperor penguin Aptenodytes forsteri (Robertson et al. 1994) are known to include a substantial proportion of benthic/benthopelagic organisms in their diet at some colonies. One gentoo penguin was also observed foraging close to the shore in very shallow water (Kooyman 1975), and another individual was caught in a fish-net while probably feeding on the sea floor (Conroy \& Twelves 1972). Finally, diving profiles and patterns together with bathymetry suggested bottom foraging in, again, the gentoo pen- 
guin (Croxall et al. 1988, Wilson et al. 1991, Robinson \& Hindell 1996), yellow-eyed penguin (Moore \& Wakelin 1997), and the emperor penguin (Ancel et al. 1992, Kooyman \& Kooyman 1995, Kirkwood \& Robertson 1997). However, only little information (or none) is available from previous studies on detailed diving profiles of the presumed benthic dives, on the quantitative importance of those dives in the foraging ecology of the species, and on a comparison of diving parameters between benthic and pelagic dives.

The aims of the present study were therefore: (1) to examine if a penguin living in a very coastal environment (the southern rockhopper penguin Eudyptes chrysocome filholi from the sheltered Baie du Morbihan, Kerguelen Archipelago) forages near or at the sea floor and, if so, (2) to quantify this behaviour and to relate it to the amount of food brought ashore to the chicks to investigate the profitability of benthic dives. A comparison of diving parameters and foraging efficiency between benthic and pelagic dives performed by the same individuals was also made to give new insight into the poorly documented benthic underwater behaviour of penguins.

\section{METHODS}

Study site, birds and diet. Fieldwork was conducted during January 1998 at Mayes Island $\left(49^{\circ} 28^{\prime} \mathrm{S}\right.$, $\left.69^{\circ} 57^{\prime} \mathrm{E}\right)$ in the Golfe du Morbihan, Kerguelen Archipelago, during the guard stage of Eudyptes chrysocome filholi. At this time, female rockhopper penguins perform daily foraging trips to feed their offspring, while males fast ashore, guarding the chicks. Females were selected opportunistically and captured in the early night hours, after chick feeding. They were fitted with time-depth recorders (TDRs), and released at their nest 15 to 20 min following capture. This timing allowed females to recover from the stress of capture and manipulation overnight before returning to sea to feed. The diving behaviour of 16 birds was investigated over 2 to 6 consecutive days during the guard stage. On their return ashore, the penguins were recaptured, TDRs were removed, and stomach contents of the 16 individuals were obtained by water offloading (Gales 1987). Birds were repeatedly flushed until the returning water was clear, indicating that the stomach was empty. In the laboratory, food analysis was performed following Tremblay et al. (1997).

Time-depth recorders. Diving behaviour was studied using electronic TDRs (Mark V, Wildlife Computers, Redmond, Washington, USA). The instruments were $9.5 \mathrm{~cm}$ long $\times 3.7 \mathrm{~cm}$ wide $\times 1.5 \mathrm{~cm}$ high, and weighed $70 \mathrm{~g}$, corresponding to about $3 \%$ of the bird's body cross-sectional area and $<3 \%$ of its body mass.
TDRs were shaped to reduce drag, following indications given in Bannasch et al. (1994). They were attached to the most caudal position on the back of the birds using quick-set epoxy adhesive and plastic ties (Kooyman et al. 1992). The TDRs contained either 128 or $512 \mathrm{kB}$ memories. They were programmed to sample depth every $2 \mathrm{~s}$ (at depths $\geq 2 \mathrm{~m}$ ) and illumination (on an arbitrary scale linearly related to $\log _{10}$ lux; Wanless et al. 1999) every $1 \mathrm{~s}$. The recording interval for depth is $<10 \%$ of the mean dive duration, and thus cannot lead to errors in dive number and dive parameters (Wilson et al. 1995). Depth resolution was $\pm 1 \mathrm{~m}$.

Diving-activity analysis and statistics. Dive-depth data were analyzed using our own software (Tremblay \& Logette, unpubl. data) to determine dive depth, dive duration, bottom time (the amount of time between 75 and $100 \%$ of the maximum depth reached), diving efficiency (bottom time/[dive duration + post-dive interval]; Ydenberg \& Clark 1989), descent and ascent rates, and to analyze depth and light parameters at the bottom of the dives. Since changes in light level at depth is an indirect measurement of animal movements, we defined activity indexes while the bird was at the bottom of the dive. During bottom time of each selected dive (see below), we counted zig-zags in depth and light (depth and light wiggles, respectively), and we measured differences in depth (or light) between consecutive records, summed all these differences, and divided the sum by bottom time (depth and light activity index, respectively). We also measured the duration between bottom times as the duration between the end of bottom time for a given dive and the beginning of bottom time for the subsequent dive. A dive was deemed to occur when the maximum depth was $\geq 3 \mathrm{~m}$ (Chappell et al. 1993).

According to dive profile, benthic dives in pinnipeds were characterized by several criteria, including a square-wave shape (i.e. a steady descent followed by extended time spent at a relatively constant depth followed by a steady ascent), the uniform maximum depth of a series of dives, and the lack of deeper dives within the series, suggesting that the sea floor limited the depth to which animals could dive (Hindell et al. 1991, Thompson et al. 1991, Le Boeuf et al. 1992, Werner \& Campagna 1995, Schreer \& Testa 1996, Gales \& Mattlin 1997). Inspection of dive profiles clearly indicated that southern rockhopper penguins performed many benthic dives according to these 3 criteria (Figs. $1 \& 2$ ), which were consequently used to select 2 data sets for subsequent analysis.

One sub-sample of benthic dives $(n=1141)$ and 1 sub-sample of non-benthic, i.e. pelagic, dives $(\mathrm{n}=$ 1141) were visually extracted from the total number of recorded dives $(n=22253)$. The same number of successive benthic dives and successive pelagic dives per 


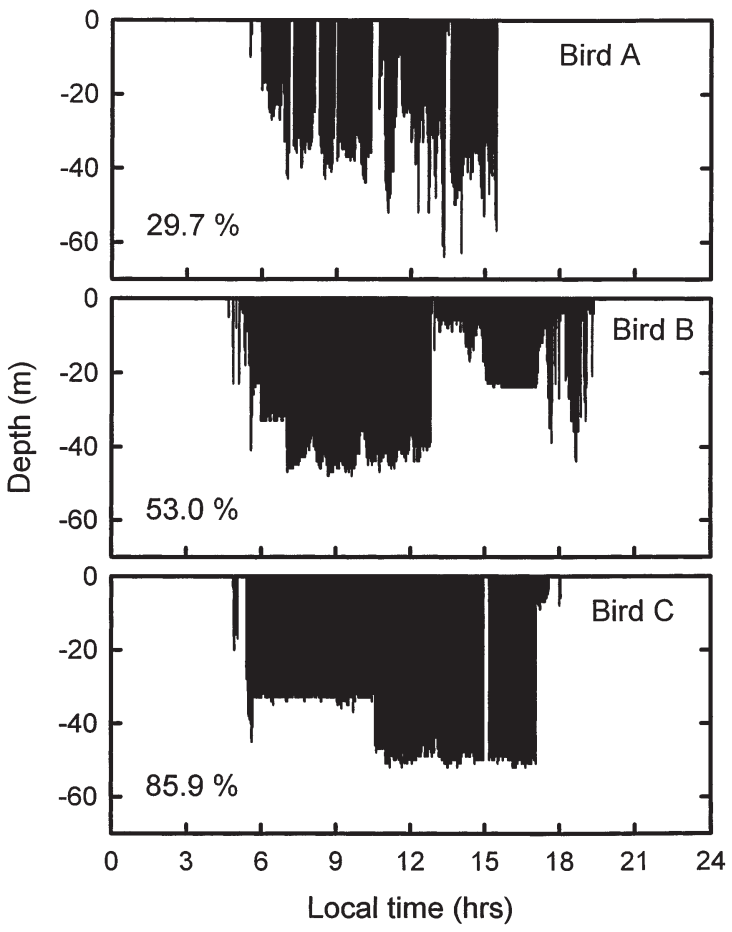

Fig. 1. Eudyptes chrysocome filholi. Diving records of daily foraging trips for 3 individual penguins (Birds A, B and C). Percentage in each panel indicates the proportion of intradepth zone (IDZ) dives for the foraging trip (see text for details)

penguin was selected in order to have similar levels of auto-correlation in the 2 sub-samples. However, because the proportion of benthic versus pelagic dives differed among individuals and among foraging trips (see 'Results'), the number of selected dives was different between birds $(71 \pm 36$ dives, range $=14$ to $132, \mathrm{n}=$ 16). As maximum depth reached during the dive essentially determined all other dive parameters (Wilson et al. 1997, Cherel et al. 1999), 2 kinds of analysis were performed. Diving parameters were first compared within each $10 \mathrm{~m}$ depth class (all the 212 dives over $50 \mathrm{~m}$ were omitted from the analysis because there were too few data in the pelagic dive data set for depth classes $>50 \mathrm{~m}$; see Fig. 4). We then compared standard deviates of dive parameters to provide an analysis independent from depth (in that case, 46 dives with an extended post-dive interval $\geq 180$ s were omitted, see Table 1). Standardization was made according to Sokal \& Rohlf (1995).

Since the birds tended to dive serially to a specific depth, consecutive dives that returned within the same depth zone were called intra-depth zone (IDZ) dives. According to the difference in vertical distance recorded in 2 rockhopper penguins foraging within the same patch (Tremblay \& Cherel 1999), depth zone was defined as the depth $\pm 10 \%$ of the maximum depth reached by the preceding dive (for example $50 \pm 5 \mathrm{~m}$ for a $50 \mathrm{~m}$ dive).

Data from pelagic and benthic dives were statistically compared with 2-tailed $t$-tests using SYSTAT 7.0 for Windows. Means $( \pm \mathrm{SD})$ are given.

\section{RESULTS}

\section{General comments}

Data were obtained from 16 female Eudyptes chrysocome filholi during 55 foraging trips which included a total of 22253 dives. All foraging trips were completed within $1 \mathrm{~d}$. As previously found for the northern subspecies during the brooding period (Cherel et al. 1999), female southern rockhopper penguins performed daily foraging trips, departing to sea in the early morning and returning ashore in the evening to feed their chicks (Fig. 1).
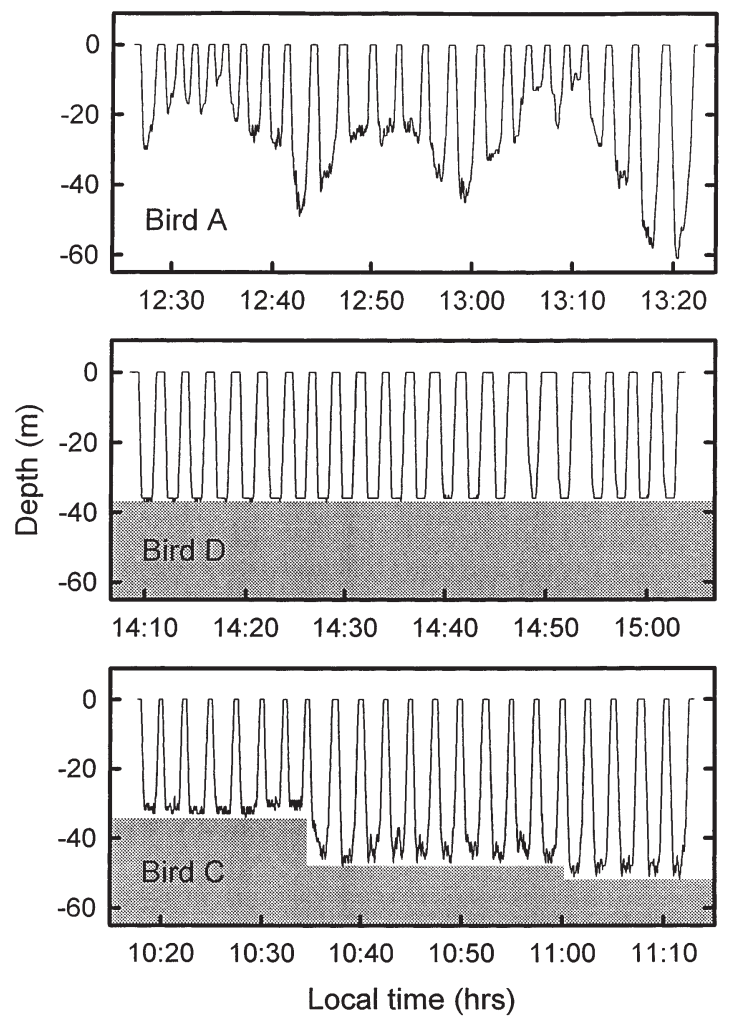

Fig. 2. Eudyptes chrysocome filholi. Records selected to illustrate various types of dive profiles. Top panel illustrates pelagic dives and middle panel benthic dives with a flat-bottom profile. Bottom panel shows benthic dives with numerous wiggles during bottom time, and it illustrates 2 steps (see text for details) within the dive series which are 14 and $4 \mathrm{~m} \mathrm{high,}$ respectively. Records from Birds A and C are parts of those from Fig. 1 at a more detailed time scale. Shading represents the presumed location of the sea floor 
Table 1. Eudyptes chrysocome filholi. Statistical comparisons between pelagic and benthic dives for all diving parameters. Values represent standardized depth-by-depth data, so differences are independent of depth (see 'Methods')

\begin{tabular}{|c|c|c|c|c|c|c|}
\hline & \multicolumn{2}{|c|}{ Pelagic dives $(\mathrm{n}=1110)^{\mathrm{a}}$} & \multicolumn{2}{|c|}{ Benthic dives $(\mathrm{n}=1126)^{\mathrm{a}}$} & \multirow{2}{*}{$\begin{array}{c}t \\
(\mathrm{df}=2234)\end{array}$} & \multirow[t]{2}{*}{$\mathrm{p}$} \\
\hline & Mean & $\mathrm{SD}$ & Mean & $\mathrm{SD}$ & & \\
\hline Descent rate & -0.217 & 1.127 & 0.214 & 0.770 & 10.552 & $<0.0001$ \\
\hline Ascent rate & -0.281 & 1.074 & 0.277 & 0.803 & 13.926 & $<0.0001$ \\
\hline Dive duration & -0.009 & 1.120 & 0.008 & 0.837 & 0.408 & 0.6837 \\
\hline Post-dive interval ${ }^{\mathrm{a}}$ & -0.059 & 1.115 & 0.059 & 0.840 & 2.823 & 0.0048 \\
\hline Dive cycle & -0.066 & 1.086 & 0.065 & 0.876 & 3.143 & 0.0017 \\
\hline Bottom time & -0.173 & 1.156 & 0.171 & 0.749 & 8.352 & $<0.0001$ \\
\hline Diving efficiency & -0.177 & 1.145 & 0.175 & 0.764 & 8.563 & $<0.0001$ \\
\hline Duration between bottom times & 0.073 & 1.117 & -0.072 & 0.835 & 3.500 & 0.0005 \\
\hline Depth wiggles & -0.102 & 1.062 & 0.107 & 0.897 & 5.031 & $<0.0001$ \\
\hline Depth-activity index & 0.172 & 1.102 & -0.170 & 0.826 & 8.302 & $<0.0001$ \\
\hline Light wiggles & -0.287 & 1.097 & 0.283 & 0.767 & 14.265 & $<0.0001$ \\
\hline Light-activity index & -0.117 & 1.112 & 0.115 & 0.832 & 5.592 & $<0.0001$ \\
\hline
\end{tabular}

Visual observation indicated variations in daily diving patterns (Fig. 1) and diving profiles (Fig. 2) among foraging trips. In some series, consecutive dives had various profiles, reached different maximum depths, and the pattern included a few very deep dives (Figs. 1 \& 2: Bird A). Such diving patterns and profiles were previously found in different species of penguins, including the northern rockhopper penguin at Amsterdam Island (Cherel et al. 1999, Tremblay \& Cherel 1999) and they are defined as pelagic dives. On the other hand, birds also dived consistently at the same depth over a long time with no deeper dives within the series (Fig. 1: Birds B and C; Fig. 2: Birds C and D). We interpreted these profiles as those of benthic dives. This behaviour was found in all the 16 birds. Benthic dives had either a flat profile (U-shaped dives, Fig. 2: Bird D), or several depth wiggles (W-shaped or ragged dives, Fig. 2: Bird C) at the bottom of the dives. Series of benthic dives were often split into several sub-series by the occurrence of a few abrupt changes (steps) in the maximum depth of dives within the series (Fig. 2: Bird C), suggesting that penguins followed changes in topography of the sea floor.

\section{Comparison between pelagic and benthic dives}

When comparing the 2 data sets of selected benthic ( $\mathrm{n}=1141)$ and pelagic $(\mathrm{n}=1141)$ dives, benthic dives reached on average deeper depths $(35.9 \pm 14.6$ vs $27.3 \pm 11.1 \mathrm{~m}$; $t$-test, $t=15.765, \mathrm{p}<0.0001)$, lasted longer $(99 \pm 20$ vs $89 \pm 25 \mathrm{~s} ; t=11.107, \mathrm{p}<0.0001)$, included a longer bottom time $(66 \pm 14$ vs $53 \pm 22 \mathrm{~s}$; $t=16.362, \mathrm{p}<0.0001)$, and had a higher diving efficiency $(0.49 \pm 0.09$ vs $0.44 \pm 0.13 ; t=10.523, \mathrm{p}<0.0001)$ than pelagic dives. Interestingly, while reaching a wider range in depth, benthic dives showed a stronger and narrower mode in dive duration, bottom time and diving efficiency than pelagic dives (Fig. 3).

Standardized values independent of dive depth (Table 1) showed no statistical difference in dive duration between pelagic and benthic dives. However, since post-dive interval was on average slightly shorter in pelagic dives, dive cycle (dive duration + post-dive interval) was also shorter for those dives. On the other hand, both descent and ascent rates were higher, and the time elapsed between 2 consecutive bottom times
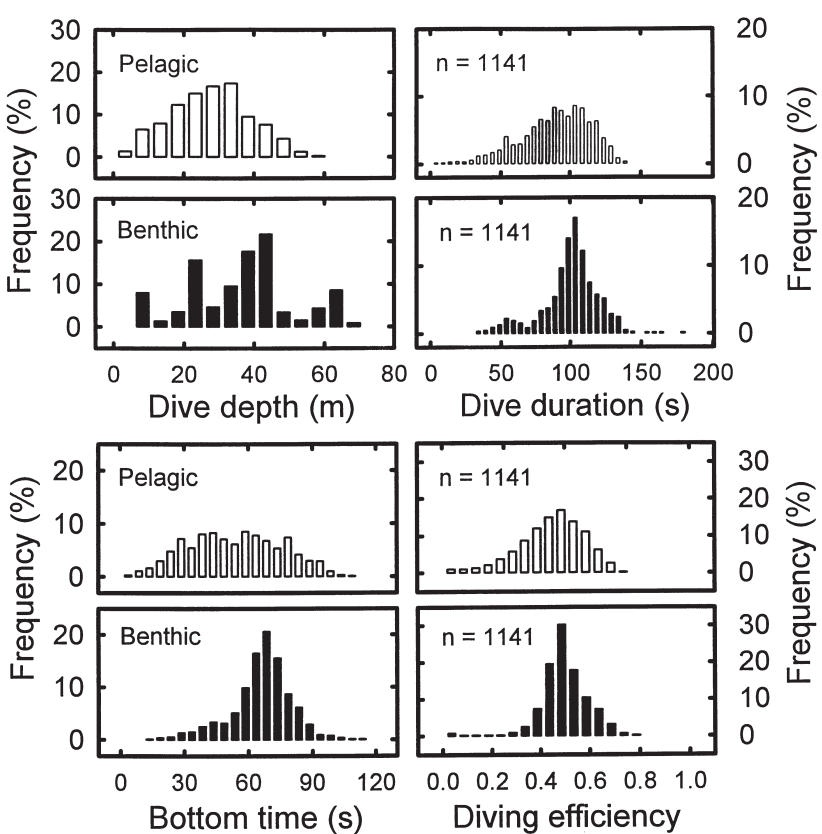

Fig. 3. Eudyptes chrysocome filholi. Frequency distribution of dive depth, dive duration, bottom time and diving efficiency for pelagic and benthic dives 


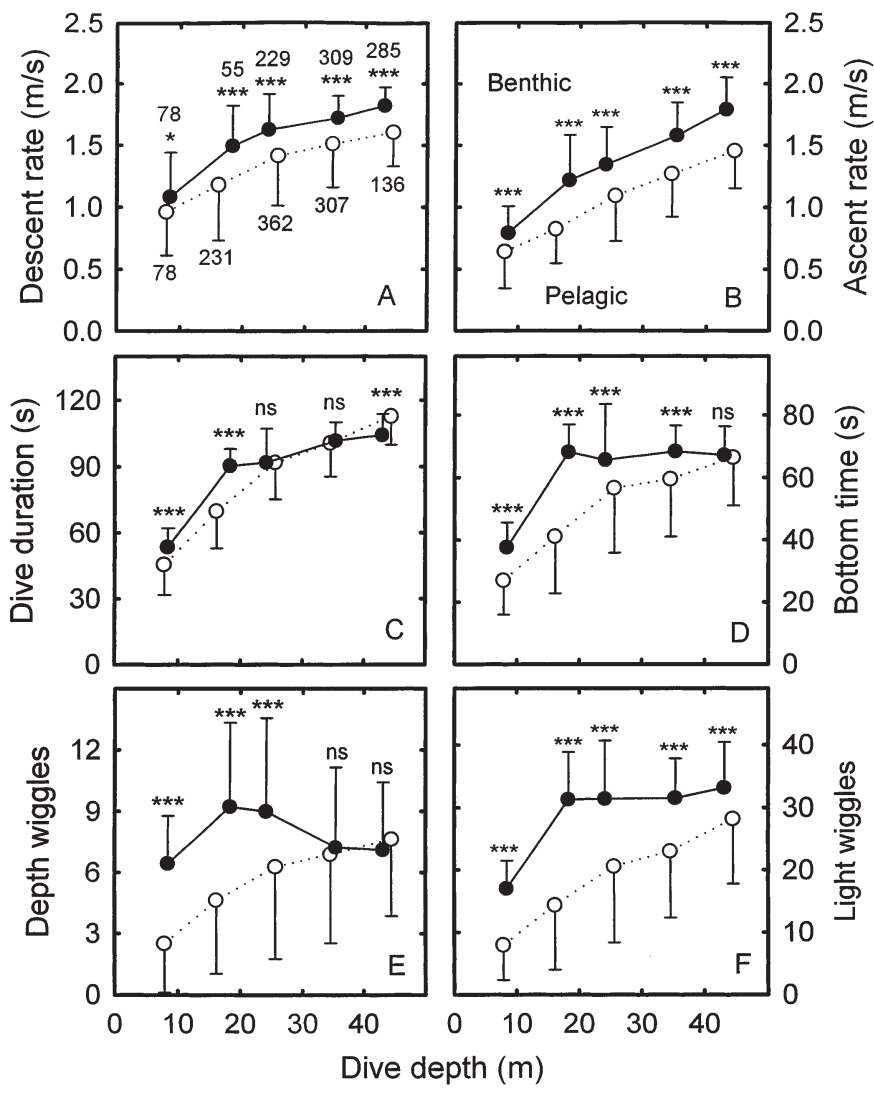

Fig. 4. Eudyptes chrysocome filholi. (A) Descent and (B) ascent rates, (C) dive duration, (D) bottom time, and the number of (E) depth and (F) light wiggles per dive in relation to dive depth for pelagic (dotted line) and benthic (solid line) dives. Numbers in (A) are those of dives in each group. Significance of differences (using $t$-test) between pelagic and benthic dives are given for each depth class: ns, non-significant; ${ }^{*} p<0.05 ;{ }^{* * *} p<0.001$

was less in benthic dives than in pelagic ones. Bottom time was longer and, consequently, diving efficiency higher in benthic dives, which were also characterized by a lower depth-activity index but a higher lightactivity index than pelagic dives (Table 1).

As previously found in northern rockhopper penguins (Cherel et al. 1999), descent and ascent rates of dives increased with increasing dive depth (Fig. 4A, B). Birds however descended and ascended faster in the water column during benthic dives than during pelagic dives at all depth classes. Dive duration also increased with increasing dive depth (Fig. 4C), but benthic dives were slightly longer for dives up to $20 \mathrm{~m}$, not statistically different in the depth range from 20 to $40 \mathrm{~m}$, and slightly shorter than pelagic dives for the deepest depths. Except for deep dives, bottom time was always higher for benthic dives (Fig. 4D). During bottom time, the number of depth wiggles was greater in benthic dives for the shallowest depth classes but no significant differences were found for the deepest dives
(Fig. 4E), whereas the number of light wiggles was always higher in benthic dives than in pelagic dives (Fig. 4E). Note that bottom time, and the number of light wiggles, followed similar patterns within each group of dives (Fig. 4D, F). Those parameters remained constant (Pearson correlation, $\mathrm{p}>0.05$ ) in the depth range from 10 to $50 \mathrm{~m}$ in benthic dives, whereas they regularly increased with depth $(p<0.0001)$ in pelagic dives.

\section{Intra-depth zone (IDZ) dives}

In agreement with the criteria to select benthic dives, the proportion of IDZ dives within the data set of benthic dives amounted to $93.7 \%$, a value much higher than that $(40.3 \%)$ calculated for the data set of pelagic dives. This means that the higher the proportion of IDZ dives, the higher the proportion of benthic dives, and thus that the proportion of IDZ dives over $40.3 \%$ can be considered as a rough index of the relative importance of benthic dives within a foraging trip.

The average percentage of IDZ dives among the 55 recorded daily foraging trips was $54.1 \pm 12.6 \%$, a value within the range of those calculated for selected pelagic and benthic dives. Only $10.9 \%(n=6)$ of the foraging trips had a proportion of IDZ dives $\leq 40.3 \%$. This does not preclude the occurrence of some benthic dives, but nevertheless strongly suggests that most of the dives during these trips were pelagic. No foraging trips had a value $\geq 93.7 \%$ (maximum value: $85.9 \%$ ) (Fig. 5). Taking into account the proportion of IDZ dives over $40.3 \%$, the estimated percentage of benthic dives averaged $15.9 \pm 11.6 \%$ (from 0.3 to $45.6 \%$ ) during the 49 trips. Note that the higher the proportion of IDZ dives, the more 'flat' the diving records of foraging trips (Fig. 1).

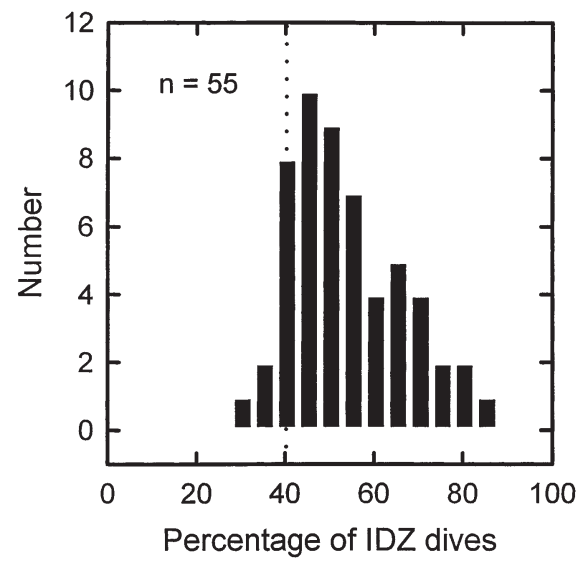

Fig. 5. Eudyptes chrysocome filholi. Frequency distribution of the proportion of IDZ dives in the 55 daily foraging trips performed by 16 birds. Dotted line represents the percentage of IDZ dives in the selected data set of pelagic dives (see text for details) 


\section{Benthic dives and the marine environment of Baie du Morbihan}

The Baie du Morbihan is a large bay (about $700 \mathrm{~km}^{2}$ ) located in the eastern part of the Kerguelen Archipelago. The central part of the bay is free of islands and has maximum depths of $50 \mathrm{~m}$, whereas the western part, where Mayes Island is located, is characterized by deeper submarine valleys (deepest depth: $190 \mathrm{~m}$ ) and numerous islands and islets. Cherel et al. (1999) estimated that the foraging range of rockhopper penguins during the guard stage averaged 5 to $6 \mathrm{~km}$. We consequently assumed that birds did not forage over a radius of more than $10 \mathrm{~km}$ around Mayes Island during the study period. Within this area $\left(214.8 \mathrm{~km}^{2}\right), 56,75,84$, and $91 \%$ of the sea surface correspond to depths down to $40,60,80$, and $100 \mathrm{~m}$, respectively. Since rockhopper penguins are able to dive up to $168 \mathrm{~m}$ (Tremblay et al. 1997), they can potentially reach the sea floor in $99 \%$ of the area in the vicinity of Mayes Island. However, the maximum depth reached by benthic dives in the present study was $67 \mathrm{~m}$, indicating that rockhopper penguins were able to forage over about $80 \%$ of the sea floor surrounding Mayes Island in January 1998.

Geological studies of the Kerguelen Islands showed that the archipelago, including the Baie du Morbihan, mainly consists of a superposition of basaltic layers (Yang et al. 1998). Erosion of this stratified structure induced a step-shaped landscape with many small cliffs located both above and below the sea surface. The frequency distribution of the thickness of basaltic lava flows from Kerguelen Archipelago is not significantly different (Kolmogorov-Smirnov, $D=0.133, \mathrm{p}=$

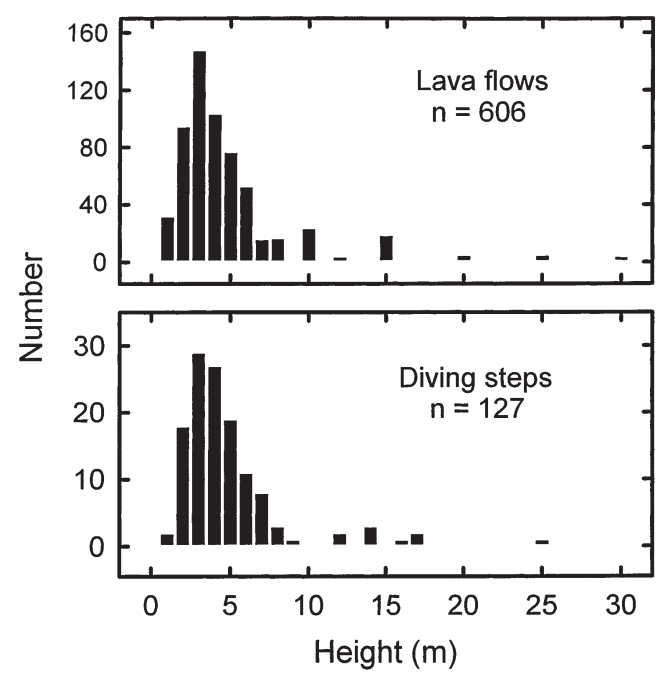

Fig. 6. Eudyptes chrysocome filholi. Frequency distribution of lava flow thickness in Kerguelen Archipelago (top panel) and frequency distribution of height of diving steps of penguins (bottom panel) (see text for details)

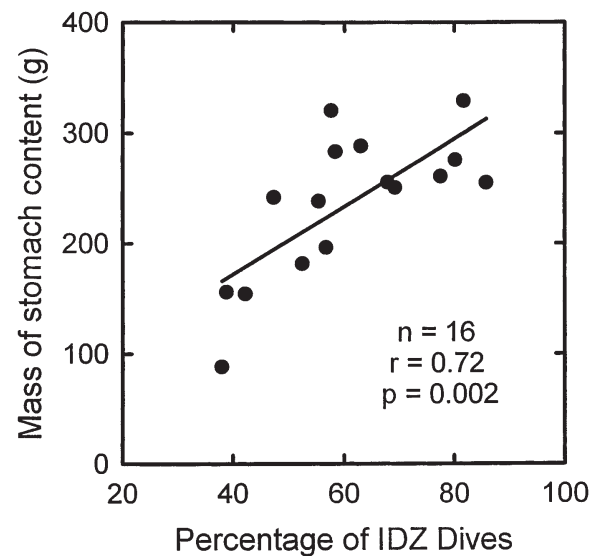

Fig. 7. Eudyptes chrysocome filholi. Mass of stomach content in relation to the percentage of IDZ dives during the corresponding daily foraging trip. Regression equation is $y=3.07 x+49.04$

0.921) from the frequency distribution of the height of steps observed within the series of benthic dives (see Fig. 2: Bird C for example) performed by rockhopper penguins during the 55 daily foraging trips (Fig. 6).

\section{Diet}

The average wet mass of the 16 stomach contents obtained from rockhopper penguins during the guard stage was $236 \pm 65 \mathrm{~g}$ (154 to $329 \mathrm{~g}$ ). The amount of food brought ashore by the females was correlated with the percentage of IDZ dives during the corresponding daily foraging trip: the greater the importance of IDZ dives, the heavier the stomach content (Fig. 7).

A total of 83330 prey items were recovered from the 16 food samples, including 83081 (99.3\%) crustaceans and 249 fish $(0.7 \%)$. By far the most abundant prey was the euphausiid Euphausia vallentini $(65.6 \%)$, which occurred in all the samples. Other important crustacean prey were the mysid shrimp Mysidetes morbihanensis $(29.6 \%$ of the total number of prey), the hyperiid amphipod Themisto gaudichaudii $(2.6 \%)$, and the calanoid copepod Paraeuchaeta antarctica $(1.9 \%)$. The fish diet included mainly unidentified postlarvae $(\mathrm{n}=227)$, the only identified fishes being Harpagifer spinosus $(\mathrm{n}=17)$, the channichthyid Champsocephalus gunnari $(\mathrm{n}=4)$ and the nototheniid Notothenia cyanobrancha $(\mathrm{n}=1)$.

\section{DISCUSSION}

To our knowledge, the present study is the first to show quantitative evidence of the importance of benthic dives for a penguin species. During the guard 
stage, female southern rockhopper penguins regularly foraged at or near the sea floor, where they caught most of their prey in the coastal waters of the sheltered Baie du Morbihan at Kerguelen Islands.

\section{Benthic diving behaviour of southern rockhopper penguins at Kerguelen Islands}

Six criteria have been used, alone or in combination, to characterize a benthic diving behaviour in airbreathing vertebrates (Hindell et al. 1991, Le Boeuf et al. 1992, Werner \& Campagna 1995, Schreer \& Testa 1996, Gales \& Mattlin 1997). They include 2 environmental criteria, i.e. the bathymetry in the area where the animals forage and the kind of prey eaten, and 4 criteria on diving profiles and patterns. First, benthic dives show a typical square-wave profile, generally with no or a few depth wiggles at maximum depth (Ushape), but some species also present numerous wiggles during bottom time (W-shape) (Thompson et al. 1991, Hochscheid et al. 1999). Second, consecutive dives vary little in their maximum depth. Third, no dives reach a deeper depth within a series, indicating that the sea floor limits the depth to which animals dive. Finally, benthic dives generally show no diurnal pattern in depth, duration and frequency, suggesting that animals do not feed on pelagic organisms performing daily vertical migration.

Excluding the last criterion, which was not investigated here due to the daily foraging habits of rockhopper penguins during the guard stage, all criteria analyzed in dive profiles and diving patterns in the present study are in close agreement with those characterizing benthic dives in the literature. Figs. 1 \& 2 illustrate the uniform depth of series of dives with no deeper dives ever seen within the series. Bathymetry of the Baie du Morbihan is also in agreement with a benthic foraging behaviour, indicating that rockhopper penguins had the diving ability to reach most of the sea floor in the vicinity of their colony. Moreover, it is noteworthy that the frequency distributions of the thickness of lava flow and of the height of diving steps observed within series of benthic dives are identical (Fig. 6). This strongly suggests that, while foraging, rockhopper penguins followed the bottom topography at a very fine scale.

Both U-shaped and W-shaped dives have been observed within the square-wave dives performed by rockhopper penguins at Kerguelen Islands. Typical Ushaped profiles can be interpreted as truly benthic dives and $\mathrm{W}$-shaped profiles as epibenthic dives, i.e. dives performed at or near the sea bed, respectively. As previously found elsewhere (Brown \& Klages 1987, Hull 1999), benthic organisms were present but they did not form the bulk of the prey in the diet of southern rockhopper penguins foraging in the Baie du Morbihan. Benthic prey were the fish Harpagifer spinosus and Notothenia cyanobrancha (Gon \& Heemstra 1990), and, more importantly, the crustacean Mysidetes morbihanensis (Ledoyer 1995). The other prey items were all pelagic organisms including the crustaceans Themisto gaudichaudii (Kane 1966) and Paraeuchaeta antarctica (Fontaine 1988), and the main food item, Euphausia vallentini (Lomakina 1966). In neritic and slope waters, euphausiids are known to aggregate near the sea floor by day and to move upwards at night (Mauchline \& Fisher 1969, Blackburn 1980, Gutt \& Siegel 1994). Moreover, it has been hypothesized that the oceanic E. vallentini attempting to migrate downwards over the shallow shelf waters would be trapped by bottom topography and thus vulnerable to predation (Perissinotto \& McQuaid 1992). Such a mechanism probably accounts for the daytime benthic diving behaviour of rockhopper penguins which fed on pelagic migrators concentrated at or near the sea floor in the coastal area of the Baie du Morbihan. Foraging on dense epibenthic/suprabenthic sound-scattering layers was similarly found in diving birds, i.e. murres Uria aalge and U. lomvia and shearwaters Puffinus tenuirostris feeding on euphausiids in the north Pacific (Coyle et al. 1992, Hunt et al. 1996).

All daily foraging trips of southern rockhopper penguins included various proportions of pelagic and benthic dives. This flexible foraging behaviour was reflected by the variable amount of IDZ dives (a rough index of the percentage of benthic dives) among the trips (Fig. 5). The positive correlation found between the proportion of IDZ dives and the mass of stomach contents (Fig. 7) emphasizes the importance of benthic dives over pelagic dives in the feeding ecology of southern rockhopper penguins. It suggests a causal link between benthic dives and the amount of food collected during the foraging trips, and thus that benthic dives were more 'profitable' for penguins than pelagic ones in terms of prey capture in the coastal waters of the Baie du Morbihan.

\section{A comparison of benthic and pelagic dives}

Optimization concepts in foraging theory predict that air-breathing animals performing benthic dives should attempt to maximize bottom time (during which predators presumably feed) with respect to transit time, because the time between the water's surface and the sea bed is not directly profitable (Wilson \& Wilson 1988). Conversely, it is advantageous for pelagic feeders to look for prey in the greatest water volume and thus to spend more time in transit between the sea 
surface and the bottom of the dives (Wilson 1991). Consequently, it is expected that ascent and descent rates, together with bottom time, should be higher in benthic dives than in pelagic ones. These theoretical aspects have been previously tested in benthic and pelagic dives performed by different species of diving birds (Wilson \& Wilson 1988, Wilson 1991) but not for different dives within a single species. We are able to provide new insight into benthic versus pelagic foraging strategy because we compared parameters of benthic and pelagic dives performed by the same individuals within the same foraging trips.

In agreement with the theory, both descent and ascent rates of rockhopper penguins were higher during benthic than during pelagic dives, resulting in a decrease in transit time, and, because the 2 groups of dives had identical duration, in an increase of bottom time for benthic dives (Table 1, Figs. $3 \& 4$ ). Since postdive intervals were only slightly longer in benthic dives, their diving efficiency was higher, and the time elapsed between 2 consecutive bottom times was shorter than in pelagic dives. Thus, during a bout of benthic dives, rockhopper penguins spent more time foraging at the bottom of the dives by minimizing the non-foraging time (transit + recovery times) through a decrease in transit time.

Unlike that of pelagic dives, frequency distribution of depths for benthic dives show several modes in rockhopper penguins. Frequency distributions of dive duration, bottom time and dive efficiency were, however, clearly unimodal with strong modes at 100-105 s, $65-70 \mathrm{~s}$ and $0.45-0.50$, respectively (Fig. 3), suggesting that there was a tendency for these parameters to be independent of dive depth. Indeed, bottom time did not vary with depth for benthic dives in the range 10-50 m (Fig. 4), indicating that $65-70$ s probably corresponded to the optimal duration of bottom time to maximize prey capture success. The decision to stop feeding in a patch during a given dive could be attributed to (1) the time to handle prey, (2) a drop in the success of capture, (3) a depletion of the resource, or (4) the need to minimize energy expenditure. Since rockhopper penguins fed on small prey swallowed underwater and performed a series of identical dives (thus presumably foraging in the same patch), the most likely explanation for stopping feeding during a dive is the energy limitation hypothesis. The aerobic dive limit of rockhopper penguins has been recently estimated at about $110 \mathrm{~s}$ (Cherel et al. 1999), a value close to the duration of the benthic dives recorded here (Figs. $3 \& 4$ ), which suggests that birds would be physiologically limited in longer dives.

To our knowledge, light wiggles were not previously used as an index of foraging activity in diving animals. Light wiggles are related to changes in the position of the bird's body with respect to the sea surface (Wanless et al. 1999) and thus to its movements while feeding. They were observed during bottom time of both benthic and pelagic dives, but they were more numerous and the light-activity index was higher during benthic dives, suggesting that penguins foraged more actively during benthic than during pelagic dives. More light wiggles in benthic dives cannot be related to the presence of kelp Macrocystis pyrifera in the area because the difference in light wiggles between pelagic and benthic dives was observed not only for shallow dives but also at deeper depths $(>20 \mathrm{~m})$ where almost no kelp occurred (Delépine 1976). Depth wiggles, i.e. vertical excursions in depth, are consistent with the animal pursuing and capturing prey in the water column during bottom time (Le Boeuf et al. 1992). In the present study, depth wiggles were on average more numerous during benthic dives. The depth-activity index was however lower in benthic dives because vertical movements during them were of smaller amplitude than during pelagic dives. This, together with the higher light-activity index in benthic dives, suggests that penguins were feeding on a thinner and probably denser epibenthic layer of euphausiids during benthic dives, and that they were foraging on thicker, but less dense swarms during pelagic dives. Feeding on prey trapped on the bottom is advantageous because crustaceans cannot escape vertically while predators return to the water surface to breathe. Consequently, predictability of prey, a crucial parameter in determining foraging strategy (Wilson 1991), is likely to be higher when feeding on an epibenthic layer of prey than when foraging in a mid-water swarm.

\section{Marine mammals and birds and the benthic environment}

Benthic dives were first recorded using electronic TDRs in pinnipeds and then in a few cetacean and seabird species. The pinnipeds included phocid seals (Thompson et al. 1991, Schreer \& Testa 1996, Lesage et al. 1999), the walrus Odobenus rosmarus (Wiig et al. 1993), and otariids (Werner \& Campagna 1995, Gales \& Mattlin 1997, Green 1997). Due to logistical and technological problems, fewer studies have investigated the diving behaviour of cetaceans using TDRs. Despite this, benthic dives have been reported as the main foraging behaviour in the beluga whale Delphinapterus leucas (Martin \& Smith 1992) and the northern bottlenose whale Hyperoodon ampullatus (Hooker \& Baird 1999).

Among birds, dive profiles and diving patterns indicative of benthic dives have been described in sev- 
eral species of cormorants (Green \& Williams 1997, Kato et al. 1998, Wanless et al. 1999), and possibly also in 1 alcid, the thick-billed murre (Croll et al. 1992). Until the present work, little was known of benthic foraging behaviour in penguins, but diving profiles together with bottom topography suggested that emperor, gentoo and yellow-eyed penguins forage both in mid-water and near the sea bed (Croxall et al. 1988, Ancel et al. 1992, Kooyman \& Kooyman 1995, Robinson \& Hindell 1996, Kirkwood \& Robertson 1997, Moore \& Wakelin 1997), and this was confirmed by the regular occurrence of benthic and benthopelagic organisms in their diet (Adams \& Klages 1989, Seddon \& Van Heezik 1990, Van Heezik 1990, Ridoux 1994, Robertson et al. 1994, Moore \& Wakelin 1997, Cherel \& Kooyman 1998). The large amount of epibenthic prey in the diet of king penguins Aptenodytes patagonicus in winter (Cherel et al. 1996) suggests that feeding near the sea floor also is an important foraging strategy for the species at that time of year. Finally, a few benthic prey have been found in the diet of Adélie Pygoscelis adeliae (Puddicombe \& Johnstone 1988, Watanuki et al. 1994), royal Eudyptes schlegeli (Hull 1999), macaroni E. chrysolophus (Brown \& Klages 1987) and African Spheniscus demersus (Randall \& Randall 1986) penguins, indicating that they sometimes forage close to the sea floor. Benthic dives therefore appear to be an important part of the foraging repertoire of at least 5 species (emperor, gentoo, yellow-eyed, king and rockhopper penguins), suggesting that feeding at or near the sea bed is probably more widespread than previously supposed in penguins.

Most species of pinnipeds engaged in a benthic feeding strategy are known to forage in neritic waters (Thompson et al. 1991, Wiig et al. 1993, Werner \& Campagna 1995, Green 1997), including the deep (300 to $500 \mathrm{~m}$ ) Antarctic (Schreer \& Testa 1996) and New Zealand (Gales \& Mattlin 1997) shelves. More oceanic species also perform benthic dives but at some locality and/or during some periods of their breeding cycle only, such as male southern elephant seals Mirounga leonina breeding on subantarctic islands and foraging near the Antarctic continent (Hindell et al. 1991). Penguin species which show, or are suspected to have, an important benthic foraging behaviour are either offshore species (the emperor and king penguins when they forage over the Antarctic and Crozet shelves, respectively; Ancel et al. 1992, Kooyman \& Kooyman 1995, Cherel et al. 1996), or more inshore species (the gentoo and yellow-eyed penguins; Croxall \& Lishman 1987, Moore \& Wakelin 1997). Rockhopper penguins from the Baie du Morbihan at Kerguelen Islands are very coastal top predators. They forage in a shallow water marine environment which contrasts with the oceanic ecosystem of Amsterdam Island, where the species performs pelagic dives only (Cherel et al. 1999, Tremblay \& Cherel 1999). Benthic versus pelagic foraging are therefore important behavioural adaptations to the local environment. Further comparative studies using electronic devices are now needed to collect information on the flexible foraging strategy of penguins and to understand how these predators cope with environmental variability in time and space.

Acknowledgements. The authors thank D. Guillaume and J. Y. Cottin for providing data on the thickness of lava flows at Kerguelen Islands, S. Caulle, O. Duriez, G. Juin and D. Secondi for their help in the field, and C. Trouvé for her help in food analysis. This work was supported financially and logistically by the Institut Français pour la Recherche et la Technologie Polaires (Programme No. 109) and the Terres Australes et Antarctiques Françaises.

\section{LITERATURE CITED}

Adams NJ, Klages NT (1989) Temporal variation in the diet of the gentoo penguin Pygoscelis papua at sub-Antarctic Marion Island. Colon Waterbirds 12:30-36

Ancel A, Kooyman GL, Ponganis PJ, Gendner JP, Lignon J, Mestre X, Huin N, Thorson PH, Robisson P, Le Maho Y (1992) Foraging behaviour of emperor penguins as a resource detector in winter and summer. Nature 360: 336-338

Bannasch R, Wilson RP, Culik B (1994) Hydrodynamic aspects of design and attachment of a back-mounted device in penguins. J Exp Biol 194:83-96

Blackburn M (1980) Observations on the distribution of $\mathrm{NyC}$ tiphanes australis Sars (Crustacea, Euphausiidae) in Australian waters. CSIRO Div Fish Oceanogr Rep 119:1-10

Brown CR, Klages NT (1987) Seasonal and annual variation in diets of macaroni (Eudyptes chrysolophus chrysolophus) and southern rockhopper (Eudyptes chrysocome chrysocome) penguins at sub-Antarctic Marion Island. J Zool Lond 212:7-28

Chappell MA, Shoemaker VH, Janes DN, Bucher TL (1993) Diving behavior during foraging in breeding Adélie penguins. Ecology 74:1204-1215

Cherel Y, Kooyman GL (1998) Food of emperor penguins (Aptenodytes forsteri) in the western Ross Sea, Antarctica. Mar Biol 130:335-344

Cherel Y, Ridoux V, Rodhouse PG (1996) Fish and squid in the diet of king penguin chicks, Aptenodytes patagonicus, during winter at sub-Antarctic Crozet Islands. Mar Biol 126:559-570

Cherel Y, Tremblay Y, Guinard E, Georges JY (1999) Diving behaviour of female northern rockhopper penguins, Eudyptes chrysocome moseleyi, during the brooding period at Amsterdam Island (Southern Indian Ocean). Mar Biol 134:375-385

Conroy JWH, Twelves EL (1972) Diving depths of the gentoo penguin (Pygoscelis papua) and blue-eyed shag (Phalacrocorax atriceps) from the South Orkney Islands. Br Antarct Surv Bull 30:106-108

Coyle KO, Hunt GL, Decker MB, Weingartner TJ (1992) Murre foraging, epibenthic sound scattering and tidal advection over a shoal near St. George Island, Bering Sea. Mar Ecol Prog Ser 83:1-14

Croll DA, Gaston AJ, Burger AE, Konnoff D (1992) Foraging 
behavior and physiological adaptation for diving in thickbilled murres. Ecology 73:344-356

Croxall JP, Lishman GS (1987) The food and feeding ecology of penguins. In: Croxall JP (ed) Seabirds: feeding ecology and role in marine ecosystems. Cambridge University Press, Cambridge, p 101-133

Croxall JP, Davis RW, O'Connell MJ (1988) Diving patterns in relation to diet of gentoo and macaroni penguins at South Georgia. Condor 90:157-167

Delépine R (1976) Note préliminaire sur la répartition des algues marines aux Iles Kerguelen. Comité Nat Fr Rech Antarct 39:153-159

Fontaine M (1988) Taxonomy and distribution of the Antarctica species group of the genus Euchaeta (Copepoda, Calanoida). Antarct Res Ser 47:27-57

Gales NJ, Mattlin RH (1997) Summer diving behaviour of lactating New Zealand sea lions, Phocarctos hookeri. Can J Zool 75:1695-1706

Gales RP (1987) Validation of the stomach-flushing technique for obtaining stomach contents of penguins. Ibis 129: 335-343

Gon O, Heemstra PC (1990) Fishes of the Southern Ocean. JLB Smith Institute of Ichthyology, Grahamstown

Green K (1997) Diving behaviour of Antarctic fur seals Arctocephalus gazella Peters around Heard Islands. Mar Mammal Res Southern Hemisphere 1:97-104

Green K, Williams R (1997) Biology of the Heard Island shag Phalacrocorax nivalis. 3. Foraging, diet and diving behaviour. Emu 97:76-83

Gutt J, Siegel V (1994) Benthopelagic aggregations of krill (Euphausia superba) on the deeper shelf of the Weddell Sea (Antarctic). Deep-Sea Res I 41:169-178

Hindell MA, Slip DJ, Burton H (1991) The diving behaviour of adult male and female southern elephant seals, Mirounga leonina (Pinnipedia: Phocidae). Aust J Zool 39:595-619

Hochscheid S, Godley BJ, Broderick AC, Wilson RP (1999) Reptilian diving: highly variable dive patterns in the green turtle Chelonia mydas. Mar Ecol Prog Ser 185:101-112

Hooker SK, Baird RW (1999) Deep-diving behaviour of the northern bottlenose whale, Hyperoodon ampullatus (Cetacea: Ziphiidae). Proc R Soc Lond Ser B 266:671-676

Hull CL (1999) Comparison of the diets of breeding royal (Eudyptes schlegeli) and rockhopper (Eudyptes chrysocome) penguins on Macquarie Island over three years. J Zool Lond 247:507-529

Hunt GL, Coyle KO, Hoffman S, Decker MB, Flint EN (1996) Foraging ecology of short-tailed shearwaters near the Pribilof Islands, Bering Sea. Mar Ecol Prog Ser 141:1-11

Kane JE (1966) The distribution of Parathemisto gaudichaudii (Guér.), with observations on its life-history in the $0^{\circ}$ to $20^{\circ} \mathrm{E}$ sector of the Southern Ocean. Discov Rep 34:163-198

Kato A, Watanuki Y, Naito Y (1998) Benthic and pelagic foraging of two Japanese cormorants, determined by simultaneous recording of location and diving activity. J Yamashina Inst Ornithol 30:101-108

Kirkwood R, Robertson G (1997) The foraging ecology of female emperor penguins in winter. Ecol Monogr 67:155-176

Kooyman GL (1975) Behaviour and physiology of diving. In: Stonehouse B (ed) The biology of penguins. MacMillan, London, p 115-137

Kooyman GL, Kooyman TG (1995) Diving behavior of emperor penguins nurturing chicks at Coulman Island, Antarctica. Condor 97:536-549

Kooyman GL, Cherel Y, Le Maho Y, Croxall JP, Thorson PH, Ridoux V, Kooyman CA (1992) Diving behavior and energetics during foraging cycles in king penguins. Ecol Monogr 62:143-163
Le Boeuf BJ, Naito Y, Asaga T, Crocker D, Costa DP (1992) Swim speed in a female northern elephant seal: metabolic and foraging implications. Can J Zool 70:786-795

Ledoyer M (1995) Mysidacés (Crustacea) de Kerguelen, Crozet et Bouvet (Océan Austral) récoltés par la Japonaise, le Marion-Dufresne (1972-82) et dans des contenus stomacaux d'oiseaux. J Nat Hist 29:601-618

Lesage V, Hammil MO, Kovacs KM (1999) Functional classification of harbor seal (Phoca vitulina) dives using depth profiles, swimming velocity, and an index of foraging success. Can J Zool 77:74-87

Lomakina NB (1966) The Euphausiid fauna of the Antarctic and notal regions. In: Andriashev AP, Ushakov PV (eds) Biological reports of the Soviet Antarctic Expedition 1955-58, Vol 2. Israël Programme for Scientific Translations, Jerusalem, p 260-342

Martin AR, Smith TG (1992) Deep diving in wild, free-ranging beluga whales, Delphinapterus leucas. Can J Fish Aquat Sci 49:462-466

Mauchline J, Fisher LR (1969) The biology of euphausiids. Adv Mar Biol 7:1-454

Moore PJ, Wakelin MD (1997) Diet of the yellow-eyed penguin Megadyptes antipodes, South Island, New Zealand, 1991-1993. Mar Ornithol 25:17-29

Perissinotto R, McQuaid CD (1992) Land-based predator impact on vertically migrating zooplankton and micronekton advected to a Southern Ocean archipelago. Mar Ecol Prog Ser 80:15-27

Puddicombe RA, Johnstone GW (1988) The breeding season diet of Adélie penguins at the Vestfold Hills, East Antarctica. Hydrobiologia 165:239-253

Randall RM, Randall BM (1986) The diet of jackass penguins Spheniscus demersus in Algoa Bay, South Africa, and its bearing on population declines elsewhere. Biol Conserv 37:119-134

Ridoux V (1994) The diets and dietary segregation of seabirds at the subantarctic Crozet Islands. Mar Ornithol 22:1-192

Robertson G, Williams R, Green K, Robertson L (1994) Diet composition of emperor penguin chicks Aptenodytes forsteri at two Mawson Coast colonies, Antarctica. Ibis 136:19-31

Robinson SA, Hindell MA (1996) Foraging ecology of gentoo penguins Pygoscelis papua at Macquarie Island during the period of chick care. Ibis 138:722-731

Schreer JF, Testa JW (1996) Classification of Weddell seal diving behavior. Mar Mamm Sci 12:227-250

Seddon PJ, Van Heezik Y (1990) Diving depths of the yelloweyed penguin Megadyptes antipodes. Emu 90:53-57

Sokal RR, Rohlf FJ (1995) Biometry: the principles and practice of statistics in biological research. Freeman, New York

Thompson D, Hammond PS, Nicholas KS, Fedak MA (1991) Movements, diving and foraging behaviour of grey seals (Halichoerus grypus). J Zool Lond 224:223-232

Tremblay Y, Cherel Y (1999) Synchronous underwater foraging behavior in penguins. Condor 101:179-185

Tremblay Y, Guinard E, Cherel Y (1997) Maximum diving depths of northern rockhopper penguins (Eudyptes chrysocome moseleyi) at Amsterdam Island. Polar Biol 17: $119-122$

Van Heezik Y (1990) Seasonal, geographical, and age-related variations in the diet of the yellow-eyed penguin (Megadyptes antipodes). N Z J Zool 17:201-212

Wanless S, Finney SK, Harris MP, McCafferty DJ (1999) Effect of diel light cycle on the diving behaviour of two bottom feeding marine birds: the blue-eyed shag Phalacrocorax atriceps and the European shag P. aristotelis. Mar Ecol Prog Ser 188:219-224 
Watanuki Y, Mori Y, Naito Y (1994) Euphausia superba dominates in the diet of Adélie penguins feeding under fast sea-ice in the shelf areas of Enderby Land in summer. Polar Biol 14:429-432

Werner R, Campagna C (1995) Diving behaviour of lactating southern sea lions (Otaria flavescens) in Patagonia. Can J Zool 73:1975-1982

Wiig O, Gjertz I, Griffiths D, Lydersen C (1993) Diving patterns of an Atlantic walrus Odobenus rosmarus rosmarus near Svalbard. Polar Biol 13:71-72

Williams TD (1995) The penguins Spheniscidae. Oxford University Press, Oxford

Wilson RP (1991) The behaviour of diving birds. In: Acta XX Congressus Internationalis Ornithologici. Christchurch. New Zealand Ornithological Congress Trust Board, Wellington, p 1853-1867

Wilson RP (1995) Foraging ecology. In: Williams TD (ed) The penguins Spheniscidae. Oxford University Press, Oxford, p 81-106

Editorial responsibility: Otto Kinne (Editor),

Oldendorf/Luhe, Germany
Wilson RP, Wilson MPT (1988) Foraging behaviour in four sympatric cormorants. J Anim Ecol 57:943-955

Wilson RP, Culik B, Spairani HJ, Coria NR, Adelung D (1991) Depth utilization by penguins and gentoo penguin dive patterns. J Ornithol 132:47-60

Wilson RP, Pütz K, Charrassin JB, Lage J (1995) Artifacts arising from sampling interval in dive depth studies of marine endotherms. Polar Biol 15:575-581

Wilson RP, Bost CA, Pütz K, Charrassin JB, Culik BM, Adelung D (1997) Southern rockhopper penguin Eudyptes chrysocome chrysocome foraging at Possession Island. Polar Biol 17:323-329

Yang HJ, Frey FA, Weis D, Giret A, Pyle D, Michon G (1998) Petrogenesis of the flood basalts forming the northern Kerguelen Archipelago: implications for the Kerguelen plume. J Petrol 39:711-748

Ydenberg RC, Clark CW (1989) Aerobiosis and anaerobiosis during diving by western grebes: an optimal foraging approach. J Theor Biol 139:437-449

Submitted: December 10, 1999; Accepted: March 28, 2000 Proofs received from author(s): September 4, 2000 